\title{
Is the Lessons tool useful to support students learning?
}

\author{
Ana Vidaurre, José M. Meseguer-Dueñas, Jaime Riera, José Molina Mateo, José \\ Antonio Gómez-Tejedor, M. Amparo Gámiz-González, Isabel Tort Ausina \\ Departament de Física Aplicada. Escola Tècnica Superior d'Enginyeria del Disseny, Universitat \\ Politècnica de València.
}

\begin{abstract}
Nowadays, Information and Communication Technologies play an important role in the teaching-learning process. Universities have incorporated different platforms specifically designed to educational institutions; among others Moodle and Sakai are being used in Spanish Universities. In particular, the Universitat Politècnica de València has adopted the PoliformaT platform, adapted from Sakai. It consists on different tools that facilitate the teaching and learning processes and the teacher-student communication. It enables teachers to improve their instructional design and it is of key importance in blended learning and flipped classroom approach.

Lessons is a specific tool available in PoliformaT, which enables the organization of the different educational resources. It combines lecture slides, video lectures (from the teacher or from others sources), exams (quizzes, self-/peer-assessment), tasks and so on. The extensive use of the online platform in the daily learning of the subject, by several teachers and different student groups, needs to pay special attention to the resources organization. In contrary case, the subject platform can become a mess, losing its usefulness.
\end{abstract}

In this paper, the utilization of Lessons by students in two first course subjects at the Universitat Politècnica de València is studied. The teachers of physics of the Aerospace Engineering Degree and electricity of Electronic and Automatic Engineering Degree have designed the course activities by means of the Lessons tool.

There are important research questions related to the Lessons tool: how often, when, and how students access to the different contents?, do they think it is useful? At a second level, one can be asked if student perceptions are related to learning outcomes. We will use students' learning tracks, student's survey and scores to answer these questions.

Keywords: ICT, Sakai tools, Physics, learning outcomes. 


\section{Introduction}

In the university's learning process, information and communication technologies play an important role (Biggs \& Biggs, 1999). Different learning platforms have been designed as a powerful tool, where the main objective is facilitate the teaching and learning processes of the students and improve the teacher-student communication (Armellini \& Jones, 2008)

Some authors (Domínguez et al., 2013; Liu, Li, \& Carlsson, 2010; Meseguer-Dueñas et al., 2016) have described the positive consequence of the students in all education levels such us: motivation, socialization, technological skills, management of information and time and sense of responsibility, when they used the learning platforms. The students are active learners rather than spectators comparing with conventional educational methodologies.

Universitat Politècnica de València has adopted the PoliformaT platform powered by Sakai. Lessons is a specific tool available in PoliformaT where the teachers and the students can used to the organization and consultation of the different educational resources. This tool provides web-based interfaces that support a wide range of activities. These include different activities like lecture slides, video lectures, exams, tasks and so on, where the student have sufficient resources for setting up standard courses. The design and organization of different tasks in Lessons must be clear and well organized to ensure a successful learning process (Rienties et al., 2012; Yániz Álvarez de Eulate \& Villardón Gallego, 2006).

In this paper, the utilization of Lessons by students in two first course subjects at the Universitat Politècnica de València is studied. The teachers of physics of the Aerospace Engineering Degree, Electricity of Electronic and Automatic Engineering Degree have designed the course activities by means of the Lessons tool. The main objective of the teacher has been carried on an appropriate design of the different tasks within this platform to motivate the student and make him participate in his teaching-learning process. It is interesting for teachers to know if lesson's tool is properly used by the students; how often and when do they consult the resources. This information can serve as feedback in the process of continuous improving.

\section{Methodology}

In this paper, the use of Lessons by students of two first course subjects at the UPV is studied. The teaching subjects are Physics for the Aerospace Engineering Degree and Electricity for Electronic and Automatic Engineering Degree. The teachers have designed 
the course activities by means of the Lessons tool following a blended teaching model. Students are asked to watch videos and perform some readings at home. Some of the classes follow a traditional lecturer scheme whereas some others follow a flip teaching (FT) model. While students perform some specific task such as solving a problem, the teacher answers the doubts individually or to small groups.

The learning design of the course is organized through the Lessons tool. It contains a general description of each unit, teacher slides, readings, videos, tasks that students have to fulfil in groups or individually, self-assessment tests, etc. All the course contents, including the lab sessions, can be found in a clear and organized way.

\section{Physics for the Aerospace Engineering Degree}

Physics subject for Aerospace Engineering Degree has 12 ECTS (European Credit Transfer and Accumulation System) and it is annual. Three of the 12 ECTS correspond to the laboratory work, being the other 9 for classroom sessions. It has 124 students enrolled divided in two groups. Part of the classes are organized in a traditional way, where the teacher explains the contents to the students, and students take notes and make some questions. In addition, in other classes, the students are required to solve some problems or task in class in small groups, with the help of the teacher. Finally, some classes follow a FT methodology, where students have to see a video or read a pdf file before coming to class, and the class is dedicated to solve questions and make an activity related with the materials that students have prepared at home. In all cases, students have all material they need to follow or prepare the class in Lessons tool.

\section{Electricity for Electronic and Automatic Engineering Degree}

Electricity is a second semester 6 ECTS subject; 1.5 of them correspond to laboratory work. 150 students divided in three groups are enrolled on this subject; one of them, with 25 students is taught in English. In the theoretical and problem classes there are four lecturers together, one in the English group and three in the other two. In the problem sessions two teacher are in the class whereas one teacher is present in the lab session of the group in English and three teachers are present in the lab sessions of the other two groups.

Part of the classes are organized in a traditional manner. The teacher explain some topic and the students have a quite passive role. Besides, students are asked to watch some videos and they are discussed more actively in the following class. The students are divided in groups of 5-6 students each and each group have to perform several tasks along the course. The content of the course is divided in six units. In each unit half of the groups have to solve a assigned problem, then they have to write it down in a comprehensive way and 
finally, one component of the group has to explain the problem to the rest of the class. The other half of the groups write a critical revision of the assigned problem. In the exposition session all students are invited to participate.

The Lessons tool also contains self-assessment exams that students fulfil as many times as they like and whenever they consider. There are also some specific class sessions devoted to work in groups and the teachers can answer doubts of the corresponding unit.

\section{Results}

\section{Physics of the Aerospace Engineering Degree}

As an average, each student has accessed 5.4 times per each hour of teaching received, as can be shown in Fig. 1. It is worth noting that $6 \%$ of students have accessed more than 10 times per teaching hour.

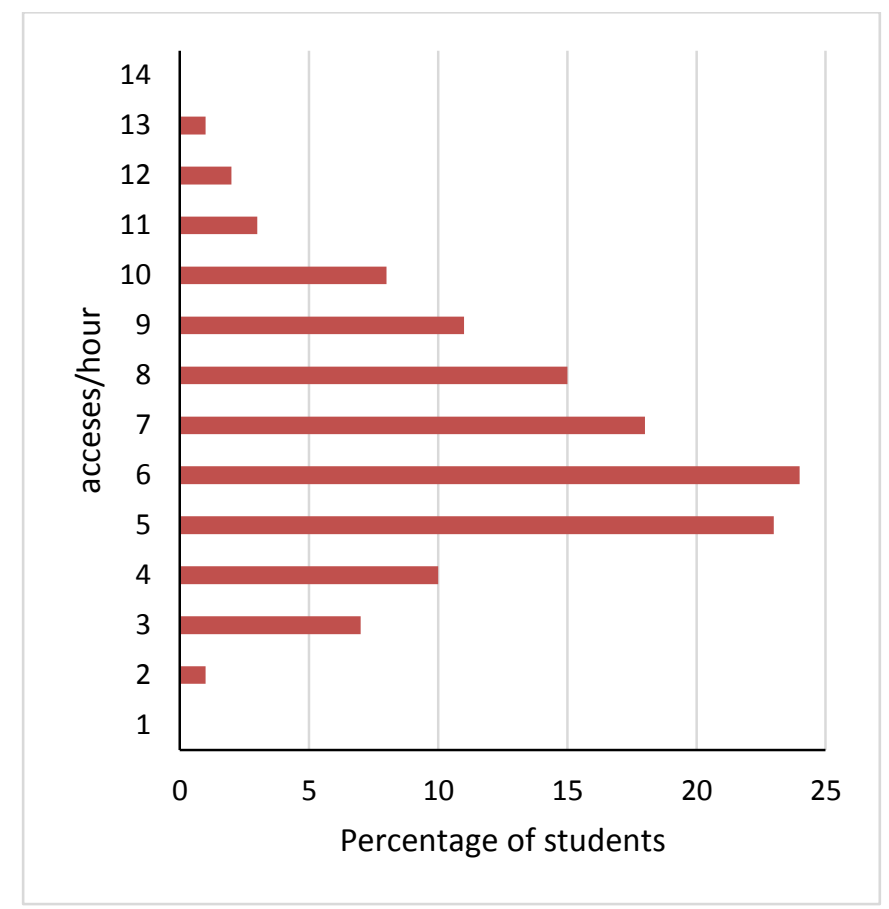

Fig. 1 Distribution of number accesses per teaching hour in the Physics subject

In the Physics subject, when the evolution of visits is studied through the year (10 months of teaching) a constant level of visits is found from the third month on, while during the 2 first months the number of visits is twice that level (see Fig. 2). This can be due to the 
needed familiarization of the students with the tool which is new for them. The annual average of the number of visits per student is 6.2 .

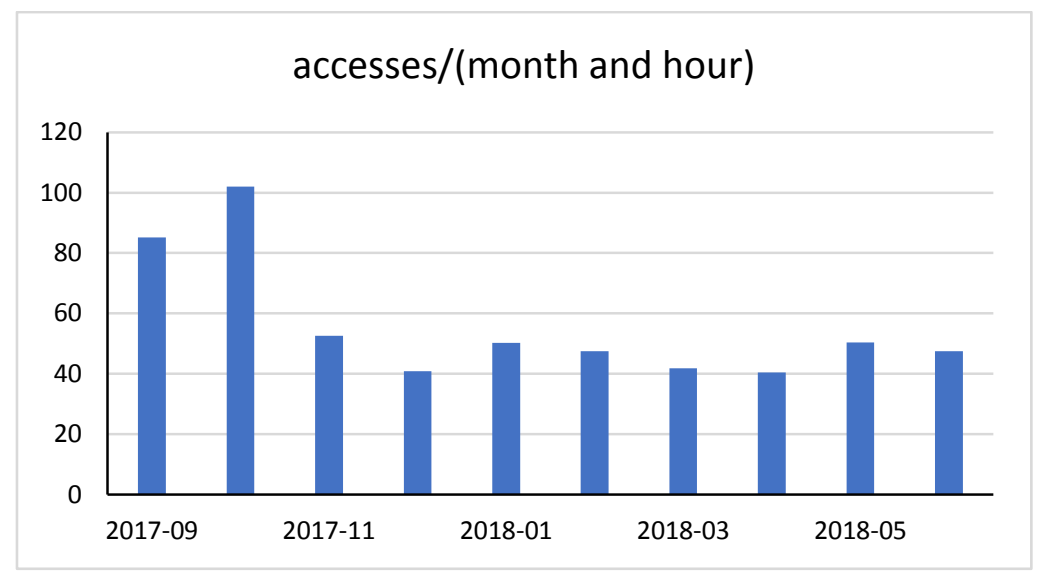

Fig. 2 Number of visits per month during the year

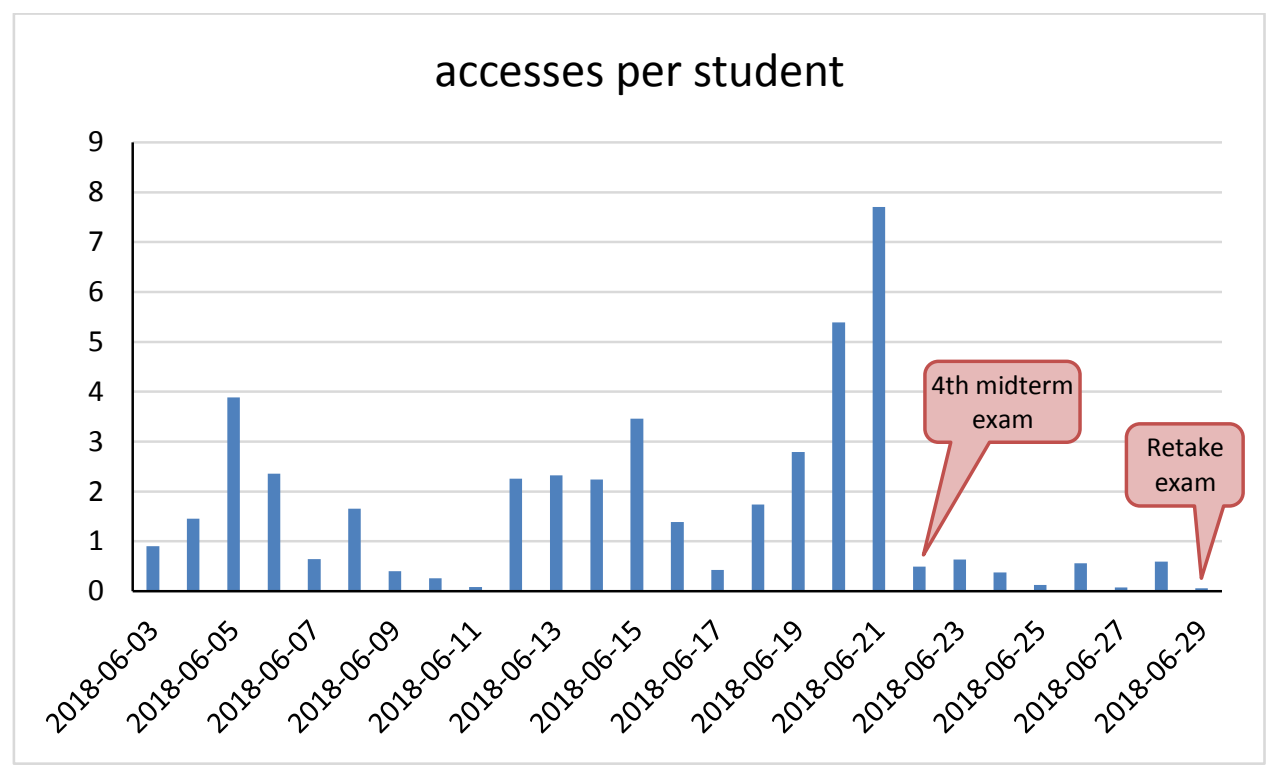

Fig. 3 Visits to Lessons during the last month of the year (June)

At this point, it is worth to study the accesses to the Lessons tool in more detail. Fig. 3 shows the accesses by day during the last month of the course. The figure shows that there 
is an irregular pattern in the number of accesses. Nevertheless, there are some events that produce a few differences in this pattern. There is an important increase of the number of accesses the previous days to the fourth midterm exam, and after this exam, the number of accesses drastically decreases, and remain more or less constant, until the retake exam when the number of accesses reduces almost to zero. The small number of accesses after the midterm exam is due to the fact that most of the students passed the subject through the four midterm exams, and only a few students have to make the makeup exam.

\section{Electricity of Electronic and Automatic Engineering Degree}

As an average, each student has accessed 8.6 times per each hour of teaching received, as can be shown in Fig. 4. In the first month of the year, the visits were up to 6.9 per each teaching hour.

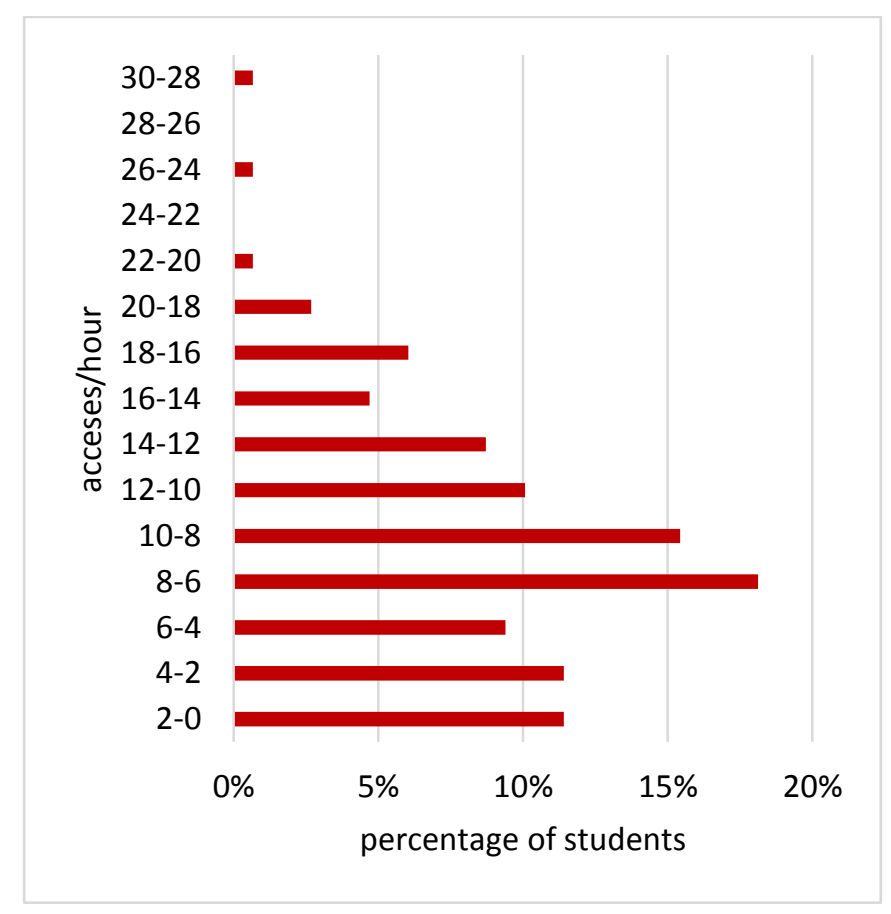

Fig. 4 Distribution of number acceses per teaching hour in the Electricity subject

$2 \%$ of the students have accesses more than 20 times per each teaching hour and $23 \%$ have accesses less than 4 times. 
Referring the laboratory, the visits to Lessons are very closely related to the day when they have to perform the lab session as the FT methodology is used and all the information in Lessons is needed for the students before, during and after the session.

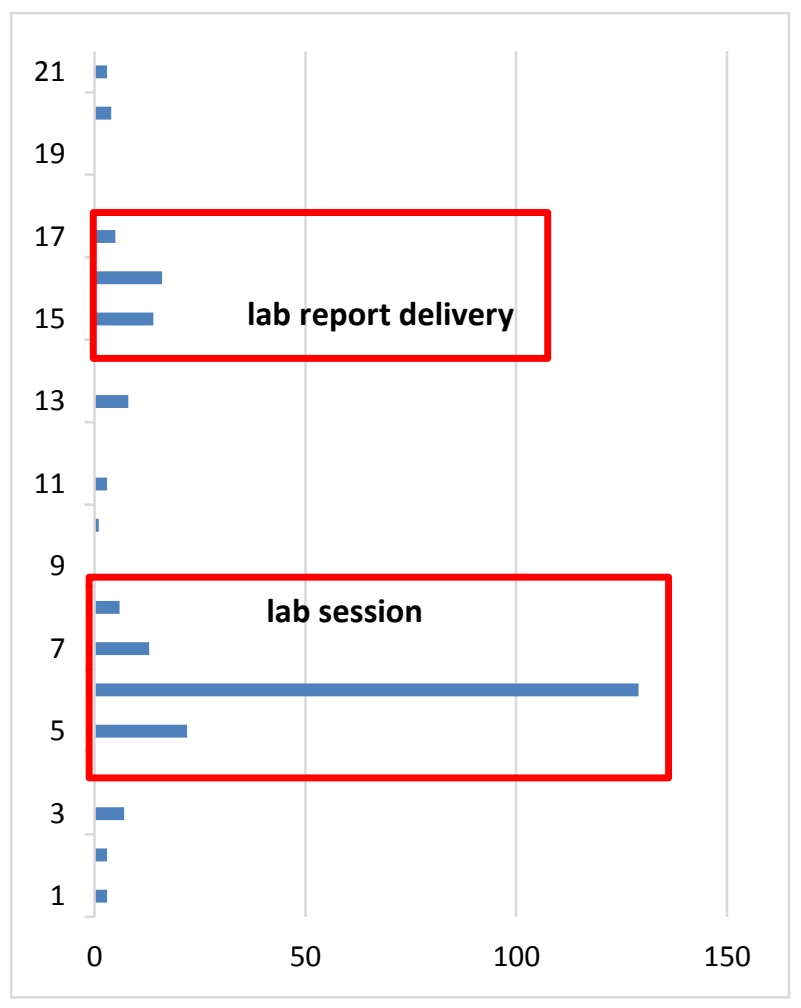

Fig. 5 Visits to the video of a laboratory experience presentation from the day when the students are advised to watch it.

There are 2 periods of the video watching: the first one is when the lab session takes place (with 1.2 visits per student). The video is watched before the session (the maximum value of visits coincides with the lab session day for the group taught in the afternoon and with the day before the session for the group taught in the morning) and during the experience performance in the session (see Fig. 5). The other maximum value in the visits correspond to the moment immediately before to the report delivery. It seems that part of the students rewatch the video to check the report just before it is delivered, as it can be observed in Fig. 5.

If an analysis considering the different teaching units is performed, and the number of teaching hours involved in each unit, students access 3.1 times per each teaching hour with a standard deviation of 1.0 (Fig. 6). 


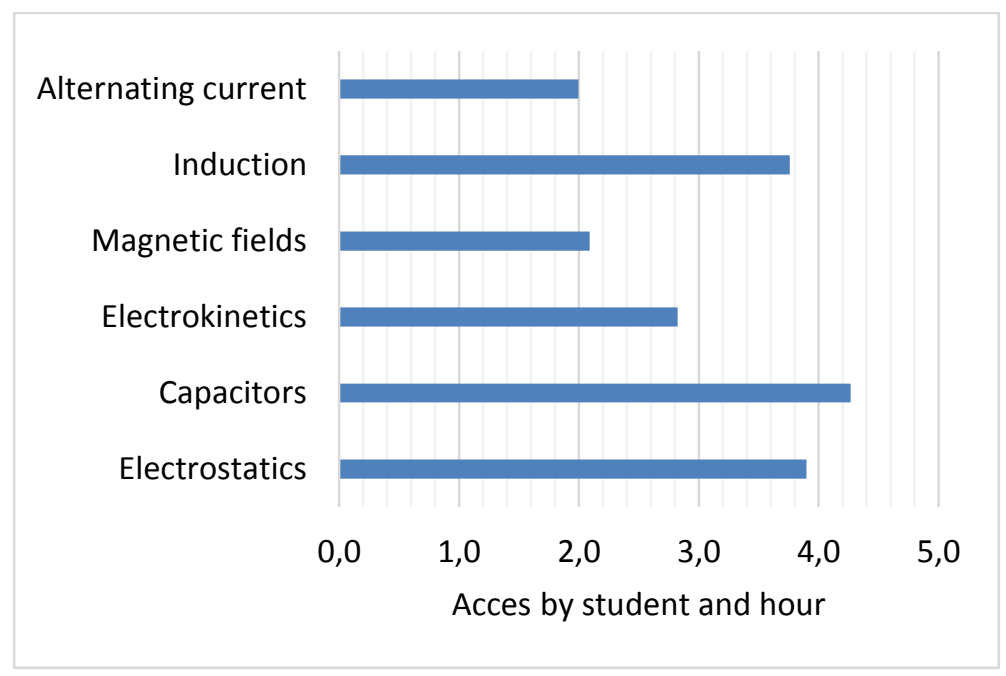

Fig. 6 Visits to Lessons per each teaching unit

All the units are accesses at least 2 times, and the shorter units have a higher number of visits. If we have a look at the unit of the Faraday Lenz law (named Induction in Fig. 6), the access is focused at the moment when it is presented in the class and in the days before the online and written exams, as shown in Fig. 7.

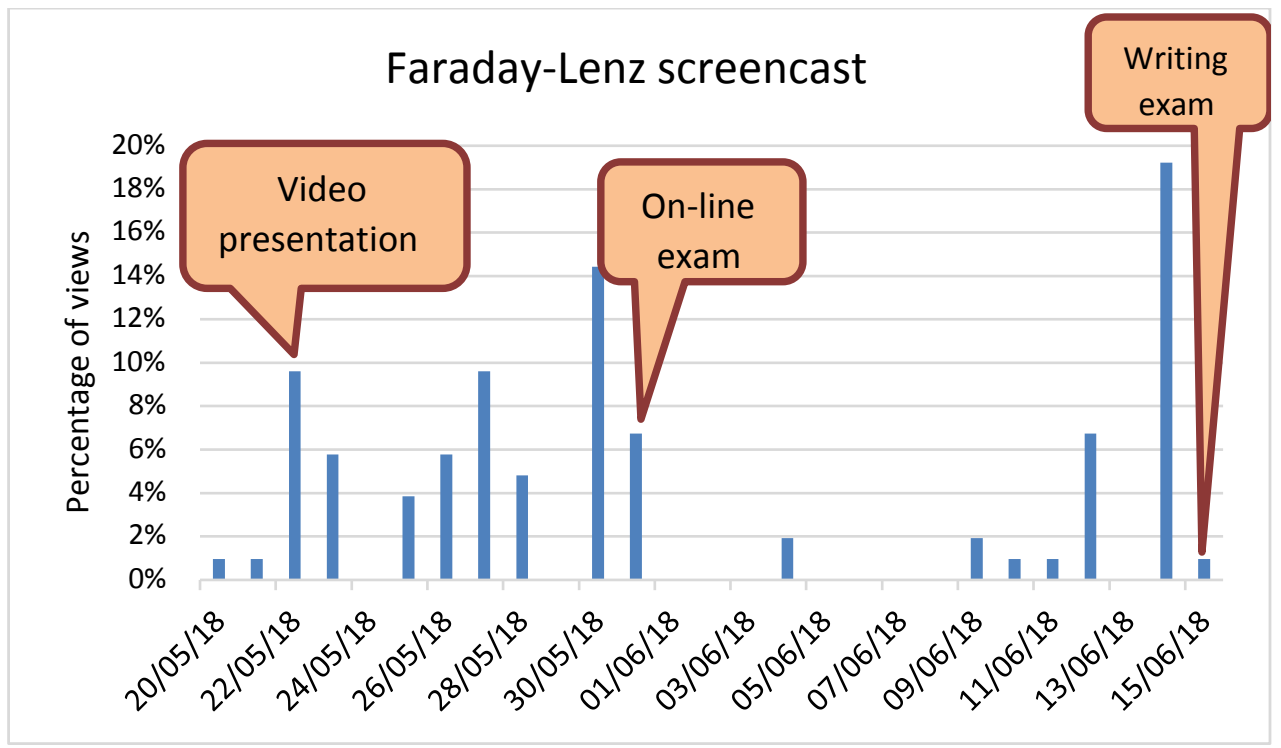

Fig. 7 Visits to the unit of the Faraday Lenz law 


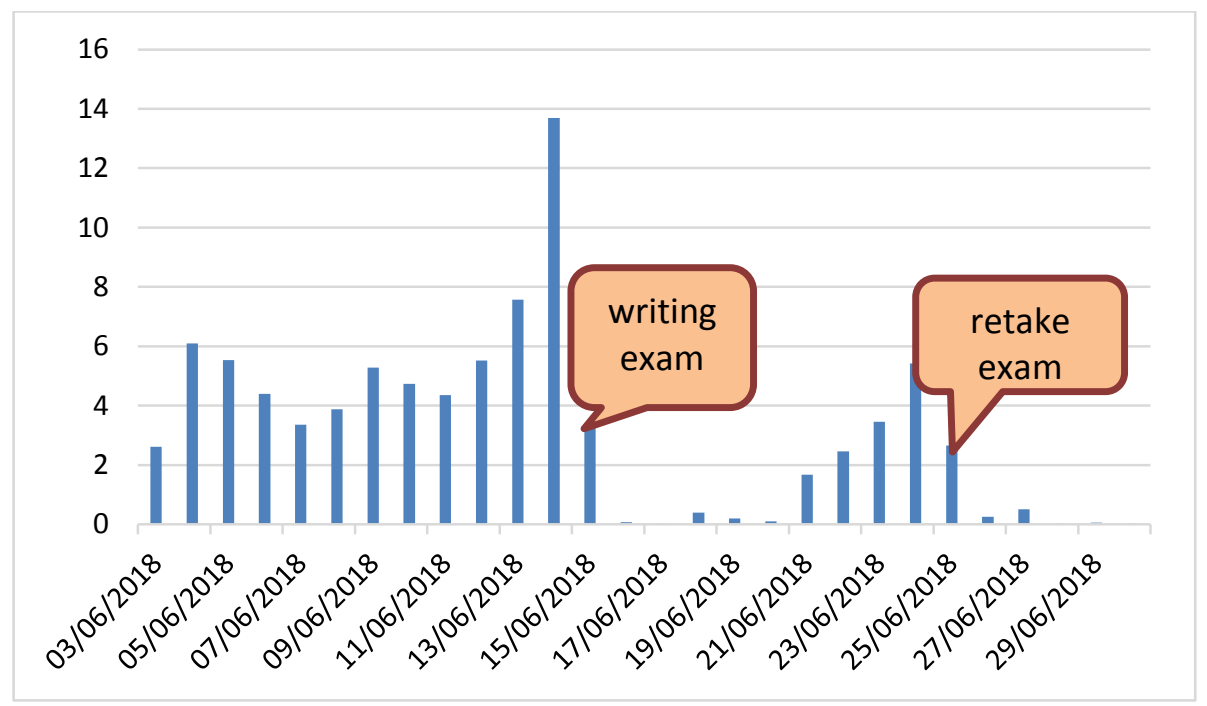

Fig. 8 Visits to Lessons during the last month of the year.

Fig. 8 shows that while during the last classes of the month (June) the daily accesses of students were around 5, this number is much more higher (up to 14) when students have to perform the last partial exam or the retake exam.

\section{Conclusions}

Lessons is a quite friendly and easy to use tool that enables lecturers to organize the learning design in blended teaching model. Allows students to access to different programmed activities; contents in video or written documents, self-assessment, tasks individual or in groups, peer review, and so on.

The visits to Lessons are very closely relates to the milestones in the course schedule; mainly, exams, laboratory sessions and date of lab report delivery.

The number of visits per student referred to the number of class hours can be a good indicator to follow the students use of the tool. However, it would be interesting to dispose of more detailed statistics about the visits, being thus able to perform a deeper study.

\section{Acknowledgment}

Authors would like to thank the Institute of Education Sciences of the Universitat Politècnica de València (Spain) for supporting the Teaching Innovation Group e-MACAFI and for the financial support through PIME Project PIME/2017/A015 


\section{References}

Armellini, A., \& Jones, S. (2008). Carpe Diem: seizing each day to foster change in elearning. Reflecting Education, 4(1), 17-29.

Biggs, J., \& Biggs, J. (1999). Assessing for learning quality: II. Practice. Teaching for Quality Learning at University. https://doi.org/10.1097/00005176-200304000-00028

Domínguez, A., Saenz-De-Navarrete, J., De-Marcos, L., Fernández-Sanz, L., Pagés, C., \& Martínez-Herráiz, J. J. (2013). Gamifying learning experiences: Practical implications and outcomes. Computers and Education, 63, 380-392. https://doi.org/10.1016/j.compedu.2012.12.020

Liu, Y., Li, H., \& Carlsson, C. (2010). Factors driving the adoption of m-learning: An empirical study. Computers and Education, 55(3), 1211-1219. https://doi.org/10.1016/j.compedu.2010.05.018

Meseguer-Dueñas, J. M., Molina-Mateo, J., Gómez-Tejedor, J. A., Ardid, M., Riera, J., Tort, I., ... Vidaurre, A. (2016). Collaborative teamwork. Relationship between student's perception and academic results. In ICERI2016 Proceedings (pp. 12771283).

Rienties, B., Kaper, W., Struyven, K., Tempelaar, D., Van Gastel, L., Vrancken, S., ... Virgailaite-Meckauskaite, E. (2012). A review of the role of Information Communication Technology and course design in transitional education practices. Interactive Learning Environments, 20(6), 563-581. https://doi.org/10.1080/10494820.2010.542757

Yániz Álvarez de Eulate, C., \& Villardón Gallego, L. (2006). Planificar desde competencias para promover el aprendizaje : el reto de la sociedad del conocimiento para el profesorado universitario. Universidad de Deusto. 